a group) show consistent performance on cognitive tests across comparable time periods. Nevertheless, we have also documented that group consistency hides significant individual variability (this can also be seen from Fig. 1 in Harvey et al's (1995) paper), and critically, that the degree of variability is related to the severity of cognitive deficits in schizophrenia.

We (Laws et al, 1998) examined whether famous face-naming deficits were consistent across time. While some patients showed little natural change across an 18-month period and little response to cueing, others showed significant change and high responsiveness to cueing. The former consisted entirely of chronically hospitalised patients; the latter were living in the community. Critically, variability across time correlated highly with the severity of cognitive baseline naming deficit $(r=0.84)$; that is, those who were less impaired at naming faces showed greater variability across time than those with more severe face-naming deficits.

We suggest, therefore, that the data of Harvey et al may not address the issue of deterioration and could reflect the severity of cognitive deficit in their patients. In other words, the extremely low baseline MMSE scores (mean $=13$ ) of Harvey et al's patients may make any change across time less likely. To detect deterioration, it is necessary to examine a group that is capable of showing deterioration. Finally, it is important to examine individual cases in greater detail to fully understand why some of Harvey et al's patients show improved MMSE scores, since this has implications for those who apparently deteriorated.

Folstein, M. F., Folstein, S. E. \& McHugh, P. R. (1975) 'Mini-Mental State': a practical method for grading the cognitive state of patients for the clinician. Journal of Psychiotric Research, 12. 189-198.

Harvey, P. D., White, L., Parrella, M., et al (1995) The longitudinal stability of cognitive impairment in schizophrenia. Mini-Mental State scores at one- and two-year follow-ups in geriatric in-patients. British Journal of Psychiatry, 166. 630-633.

Laws, K. R. \& McKenna, P. J. (1997) Psychotic symptoms and cognitive deficits: what relationship? Neurocose. 3. $41-49$.

-, - Kondel, T. K. (1998) On the distinction between access and store disorders in schizophrenia: a question of deficit severity? Neuropsychology, in press.

Keith R. Laws Department of Psychology, University of Hertfordshire. Hatfield Campus, College Lane, Hatfield, Herts ALIO 9AB

Tejinder K. Kondel Academic Department of Psychiatry, Charing Cross and Westminster Medical School, London

\section{Closing the gap between research and practice}

Sir: I read with interest the paper by Geddes \& Harrison (1997) on evidence-based medicine (EBM). They have shown that EBM is no less relevant to psychiatry than to any other medical specialty.

EBM is not simply a British (Kendell, 1997) or American initiative. Public health care in Hong Kong is managed by the Hospital Authority, a quasi-governmental body receiving a budget from the government but functioning outside the civil service itself. Annual plans on service provision are drawn up. Since a couple of years ago, we have been required to cite and rate clinical evidence according to a hierarchy very similar to that laid out in Table 1 of Geddes \& Harrison's paper. After fumbling with the concept for some time, we have gradually realised the importance of EBM in underpinning our bids for resources. We cannot help echoing Geddes \& Harrison's advice of adopting EBM before it is foisted upon us.

Geddes, J. R. \& Harrison, P. J. (1997) Closing the gap between research and practice. British journal of Psychiatry, 171. 220-225.

Kendell, R. (1997) The College and 'clinical effectiveness'. Psychiotric Bulletin. 21. 385-386.

W. N. Tang Department of Psychiatry, Pamela Youde Nethersole Eastern Hospital, 3 Lok Man Road, Chai Wan. Hong Kong

\section{Doctors' dress}

Sir: We read with interest the paper by Gledhill et al (1997) on attitudes and preferences in relation to dress and address in a sample of psychiatric in-patients. As part of a larger study (Jones et al, 1997) of adolescent health needs we invited healthy adolescents to respond in free text to the question "what is your ideal doctor like?". We received 451 answers, 153 adolescents specifically commenting on doctors' dress. Of these, $53 \%$ favoured casual clothes, with $47 \%$ stating that doctors should be smart or well-dressed. Only a few adolescents spontaneously mentioned that doctors should wear white coats. Several respondents mentioned personal hygiene stating that doctors should be "clean and not smelly".

When describing their ideal doctor, $60 \%$ of adolescents in our survey sponta- neously mentioned personality, the majority saying that doctors should be friendly, easy to talk to and sympathetic. The study by Gledhill et al found that despite the fact that wearing jeans was associated with these qualities, they were the least favoured dress option among their sample group. Perhaps a good rapport with their doctor is a higher priority on the adolescents' agenda than on the psychiatric patients' agenda, or perhaps, as Gledhill et al suggest, the wearing of white coats may help to define the boundary between the internal and external worlds for psychiatric patients.

Doctors dress and terms of address is a fascinating area, with different age groups and categories of patients having different expectations. If we are going to maximise doctor-patient communication, and thereby increase patient satisfaction, we need to be aware of their expectations.

Gledhill, J. A., Warner, J. P. \& King, M. (1997) Psychiatrists and their patients: views on forms of dress and address. British journal of Psychiatry. 17I, 228-232.

Jones, R., Finlay, F., Simpson, N., et al (1997) How can adolescents health needs and concerns best be met? British journal of General Practice. 47. 631-634.

F. Finlay, R. Jones Bath and West Community NHS Trust, Bath NHS House, Child Health Development, Newbridge Hill, Bath BAI 3QE

Sir: We read with interest the recent paper on psychiatrists' dress (Gledhill et al, 1997). We undertook similar research in 1992. The purpose of our study was to assess whether the channels of non-verbal communication (attire, facial expression and posture) played a role in attributing the personality traits of competence, trustworthiness and ability to care to general practitioners.

One hundred and forty patients waiting to see their general practitioner were shown a series of photographs depicting either a sitting male or female doctor in five different dress styles, varying in formality from white coats to jeans. For each dress style there were two options for posture, relaxed or tense, and two options of facial expression, smiling and nonsmiling. Subjects sorted the pictures on three dimensions: 'competence', 'trustworthy' and 'caring'.

We found that although formality of dress was important for patients in assessing competence and trustworthiness of male doctors, facial expression was more 